\title{
ANÁLISE DAS MANIFESTAÇÕES PATOLÓGICAS EM FACHADAS POR MEIO DE INSPEÇÃO COM VANT
}

\author{
ANALYSIS OF PATHOLOGICAL MANIFESTATIONS ON FAÇADES \\ AIDED BY UAV
}

\author{
Patricia Geittenes Tondelo ${ }^{1}$ \\ Universidade Federal de Santa Catarina, Florianópolis, SC, Brasil, ptondelo@gmail.com \\ Fernando Barth ${ }^{2}$ \\ Universidade Federal de Santa Catarina, Florianópolis, SC, Brasil, fernando.barth@ufsc.br
}

\begin{abstract}
Resumo
A altura dos edifícios cria locais de difícil acesso que podem ter sua degradação mais acelerada pela falta de equipamentos hábeis para realização de inspeções prediais. Este artigo busca analisar os aspectos construtivos e as manifestações patológicas das fachadas industrializadas por meio de inspeções auxiliadas por Veículos Aéreos Não Tripulados (VANTs). A análise dos aspectos construtivos abrangeu visitas técnicas a edificação e observações realizadas no projeto arquitetônico da fachada industrializada. A análise das manifestações patológicas abrangeu a proposição e o teste de um método de inspeção para identificar as anomalias do revestimento externo. Com relação aos aspectos construtivos, observou-se que o projeto destas vedações exige níveis de detalhamento, tais como a paginação das fachadas, acompanhamento da produção e montagem dos painéis, assim como controle das juntas. Com relação ao método de inspeção testado, a técnica de obtenção das imagens por meio da estabilização do drone em pontos pré-determinados se mostrou mais eficiente que a técnica de frames em voos pré-definidos. Os resultados apontaram que a falta de detalhamento do projeto de fachada ocasionou falhas com relação à configuração dos orifícios de ventilação da câmara de ar e o aparecimento de manifestações patológicas prematuras. Por fim, conclui-se que os processos de inspeção com VANT podem contribuir para maior controle, precisão e periodicidade no monitoramento do comportamento das fachadas ao longo da sua vida útil, produzindo assim edifícios mais eficientes ambientalmente e resistentes à obsolescência.
\end{abstract}

Palavras-chave: Tecnologia da arquitetura. Fachadas. Inspeções. VANT.

\begin{abstract}
The height of buildings creates places of difficult access that may have their degradation more accelerated by the lack of equipment capable of carrying out inspections of buildings. This article aims to analyze the constructive aspects and the pathological manifestations of the industrialized façades through inspections assisted by Unmanned Aerial Vehicles (UAVs). The analysis of the constructive aspects covered technical visits to the building and observations made in the architectural design of the industrialized façade. The analysis of the pathological manifestations covered the proposition and the test of an inspection method to identify the external coating anomalies. Regarding the constructive aspects, it was observed that the design of these gaskets requires detailed levels, such as façade paging, production, and panel assembly monitoring, as well as joint control. Regarding the tested inspection method, the technique of obtaining the images using the stabilization of the drone at predetermined points proved to be more efficient than the technique of frames in pre-defined flights. The results pointed out that the lack of detail of the façade design caused failures concerning the configuration of the ventilation holes of the air chamber and the appearing of early pathological manifestations. Finally, it can be concluded that the UAV inspection processes can contribute to greater control, precision, and periodicity in the monitoring of façade behavior over its useful life, thus producing buildings that are more environmentally efficient and resistant to obsolescence.
\end{abstract}

Key words: Architecture technology. Façades. Inspections. UAV.

How to cite this article:

TONDELO, Patricia Geittenes; BARTH, Fernando. Análise das manifestações patológicas em fachadas por meio de inspeção com VANT. PARC Pesquisa em Arquitetura e Construção, Campinas, SP, v. 10, p. e019009, fev. 2019. ISSN 1980-6809. Disponível em: <https://periodicos.sbu.unicamp.br/ojs/index.php/parc/article/view/8652817>. Acesso em: 26 fev. 2019. doi:https://doi.org/10.20396/parc.v10i0.8652817. 


\section{Introdução}

Os subsistemas construtivos que integram as fachadas devem ponderar aspectos relativos ao seu desempenho geral, incluindo fatores relacionados aos aspectos construtivos, tais como o nível de industrialização, automatização e adequação ambiental, assim como aspectos relacionados aos métodos e técnicas de inspeção e manutenção. A ponderação destes fatores pode resultar em projetos mais flexíveis com relação às modalidades de construção, ao uso e a operação, bem como produz edifícios mais ambientalmente eficientes e resistentes à obsolescência.

Observa-se que os sistemas construtivos que compõem as fachadas podem apresentar degradação mais acelerada que as partes protegidas do edifício, pois ficam diretamente expostos aos agentes ambientais. A altura dos edifícios e a falta de inspeções são outros fatores que podem acelerar a degradação do invólucro das edificações, uma vez que a altura cria locais de difícil acesso e que demandam gastos com a locação de equipamentos e ferramentas para a realização de inspeções e manutenções.

Nesse contexto, observa-se a recente habilitação de Veículos Aéreos Não Tripulados (VANT), ou drones, no setor da construção civil. Embora o uso destes equipamentos como ferramenta de inspeção ainda não esteja normalizado, existem diversos estudos que buscam indicar um método, porém mostra-se necessário desenvolver pesquisas que validem os estes métodos desenvolvidos. Neste segmento destacam-se os estudos desenvolvidos por Eschmann et al. (2012), no qual foram abordadas análises das etapas que envolvem os métodos de inspeção com drones, e os estudos de Guia e Pereira (2016), que buscaram mostrar a aplicação da robótica móvel no contexto de inspeção de fachadas.

Com relação às fachadas industrializadas, diversos são os estudos que abordaram os aspectos relativos a durabilidade deste subsistema construtivo com enfoque nas manifestações patológicas dos revestimentos externos, porém, pouco se tem tratado sobre os processos de inspeção e manutenção. Albuquerque (2013) realizou pesquisas sobre as principais manifestações patológicas e sobre o comportamento dos revestimentos fenólicos aplicados nas fachadas industrializadas com câmara de ar. Thébault et al. (2017) realizaram pesquisas relacionadas aos defeitos típicos associados aos processos de manufaturação das placas de laminados fenólicos. Com relação ao comportamento das juntas dos revestimentos de fachada, Barth e Vefago (2016) estudaram a influência de fatores externos no desgaste dos selantes aplicados nas juntas entre placas de revestimento de fachadas. Mas et al. (2011) estudaram o comportamento das juntas abertas frente às chuvas em fachadas industrializadas com câmara de ar convectiva e propuseram algumas recomendações técnico-construtivas. Neste segmento, porém, com enfoque nos fixadores, Carramiñana et al. (2011) realizaram experimentos com fixadores metálicos aplicados em revestimentos pétreos e elencaram algumas características que devem ser consideradas durante a escolha de um bom sistema de fixação.

Diante do exposto acima, observa-se que tanto a tecnologia de drones quanto a tecnologia de fachadas industrializadas com câmara de ar são recentes no Brasil e carecem de estudos mais aprofundados. Nesse contexto, este artigo busca analisar os aspectos relativos a durabilidade das fachadas industrializadas com câmara de ar, dando ênfase nos processos de inspeção. Para tanto utilizou-se um estudo de caso no qual foram analisados os aspectos construtivos por meio de uma descrição gráfica dos subsistemas que compõem a fachada industrializada com base no projeto arquitetônico, bem como foi proposto e testado um método de inspeção do revestimento externo utilizando drones. Esse artigo baseia-se nos levantamentos de 
dados da dissertação de mestrado de Tondelo (2018), em que foram realizadas análises dos processos de inspeção e manutenção de fachadas industrializadas com câmara de ar em edifícios no litoral catarinense.

\section{Caracterização das fachadas industrializadas com câmara de ar}

As fachadas industrializadas com câmara de ar representam um tipo particular de subsistemas de vedações externas. Simplificadamente, esta vedação é formada por uma estrutura composta por vários subsistemas e elementos construtivos que são dispostos de modo a criar uma câmara de ar interna. A Figura 1 apresenta uma esquematização genérica dos subsistemas construtivos que tradicionalmente compõem as fachadas industrializadas com câmara de ar explicitando a sequência de montagem da fachada.

Figura 1 - Modelo dos subsistemas e elementos construtivos que tradicionalmente compõem as fachadas industrializadas com câmara de ar

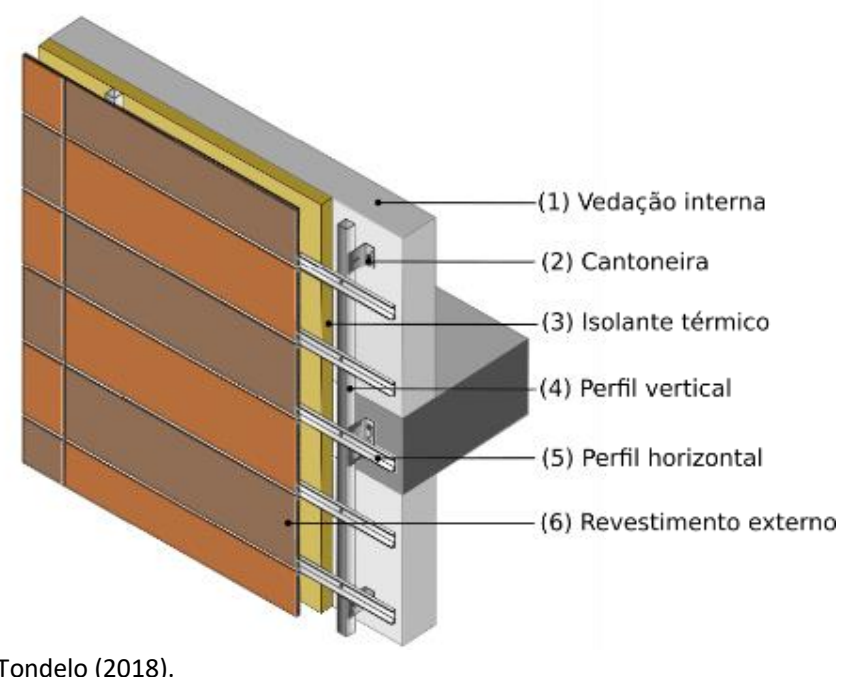

Fonte: Tondelo (2018).

Após realizada a vedação interna (1), inicia-se o processo de instalação da fachada, no qual, primeiramente, são fixadas as cantoneiras (2) para então fixar a camada do subsistema isolante térmico (3). Posteriormente são fixados os perfis de sustentação do revestimento externo nas cantoneiras (4) e (5). Por último são ancoradas as placas de revestimento nestes perfis (6).

A câmara de ar pode ser estática ou possuir orifícios de ventilação que a tornem convectiva, conforme ilustram os modelos esquemáticos da Figura 2. No caso da câmara convectiva, o ar entra e sai da câmara por orifícios de ventilação localizados nas juntas ou no topo e na base do revestimento externo. As fachadas industrializadas cujas aberturas para circulação do ar localizam-se nas juntas entre os painéis são classificadas como Fachadas Ventiladas de Juntas Abertas (a) e (c), enquanto as fachadas cujas aberturas estão apenas na parte inferior e superior do revestimento externo são classificadas como Fachadas Ventiladas de Juntas Fechadas (b) (SANJUAN et al., 2011; IBAÑEZ-PUY et al., 2017). No caso de fachadas industrializadas com câmara de ar cujas juntas e os orifícios superiores e inferiores são fechados (d), cria-se um núcleo de ar estático entre o revestimento externo e a vedação interna que não gera benefícios tanto para os períodos de verão como de inverno. 
Figura 2 - Cortes esquemáticos ilustrando os orifícios de acesso e saída do ar pelo revestimento externo

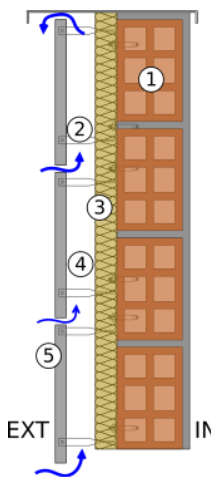

(a)

Juntas: Abertas Topo/base: Abertos

LEGENDA:

(1) Vedação

(2) Inserte

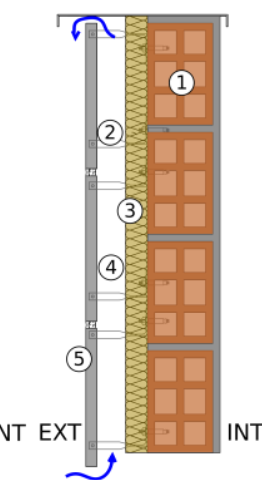

(b)

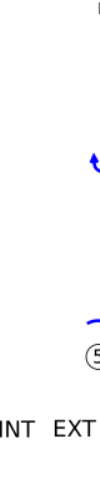

Juntas: Fechadas Topo/base: Abertos

Câmara de ar convectiva

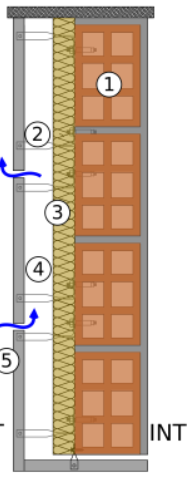

(c)

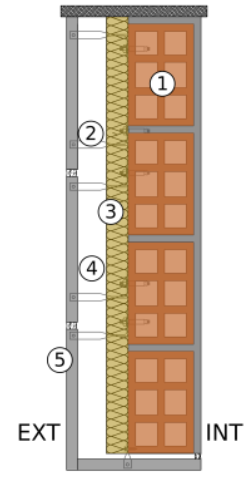

(d)

Juntas: Fechadas Topo/base: Fechados

Câmara de ar estática

Fonte: Tondelo (2018)

\section{Inspeção de fachadas auxiliada por VANT}

A finalidade das técnicas de inspeção é a determinação das falhas, anomalias ou manifestações patológicas consequentes do uso, operação ou manutenção que possam afetar algum dos aspectos relevantes à vida útil de uma edificação (GOMIDE; FAGUNDES NETO; GULLO, 2009). As inspeções podem ser classificadas como preventivas ou corretivas. As inspeções preventivas são caracterizadas por vistorias programadas e periódicas com o objetivo de evitar que as manifestações patológicas adquiram proporções que influenciem significativamente no desempenho, enquanto as inspeções corretivas caracterizam-se pela inspeção do subsistema após a instalação da manifestação patológica. Independentemente do tipo adotado, o propósito das inspeções das manifestações patológicas é identificar de modo sistemático as anomalias e suas prováveis causas com o intuito de fornecer subsídios suficientes para intervenções de reparo e manutenção que objetivam impedir a obsolescência precoce do subsistema construtivo examinado.

Dentre as técnicas utilizadas para inspecionar os edifícios, a visual caracteriza-se como a mais difundida devido ao seu caráter não-destrutivo, simplicidade de execução e instantaneidade dos resultados. Lichtenstein (1986) pontua que para aplicação desta técnica, mostra-se essencial que o pesquisador utilize os cinco sentidos, em especial a visão, aliados aos equipamentos disponíveis. Para este autor, os equipamentos, quando bem utilizados, funcionam como uma espécie de prolongamento da capacidade do técnico de apreender a realidade.

No que tange os equipamentos, inúmeros são os instrumentos tecnológicos que podem ser utilizados para auxiliar as inspeções visuais, tais como o uso de máquinas fotográficas tradicionais ou instrumentos específicos, como as câmeras termográficas, os lasers, os scanners e atualmente os Veículos Aéreos Não Tripulados (ESCHMANN et al., 2012).

Com relação às causas das manifestações patológicas, Carrió (1997) afirma que estas podem ser divididas em dois grandes grupos: diretas e indiretas. As causas diretas constituem a origem imediata da manifestação patológica, como, por exemplo, esforços mecânicos, agentes atmosféricos, contaminação, entre outros. Por outro lado, as causas indiretas abrangem os erros e defeitos de projeto e execução, tais como falta 
ou falha de detalhamento construtivo, escolha de materiais inadequados, ou ainda, defeitos de fabricação e erros de aplicação dos materiais.

A partir da identificação das anomalias e suas causas torna-se possível obter o diagnóstico indicando a correção necessária. No entanto, de modo a concentrar os estudos no objetivo deste artigo, optou-se pelo desdobramento baseado na identificação das manifestações patológicas e suas prováveis causas, sem necessariamente propor um diagnóstico.

\section{Materiais e método da inspeção}

A Figura 3 mostra os materiais utilizados na inspeção do estudo de caso: o Drone Phantom 3, a câmera fotográfica, o controle remoto e o celular smartphone. Observa-se que a fixação da câmera garante um raio máximo de giro de $180^{\circ}$ entre a parte frontal e posterior do equipamento.

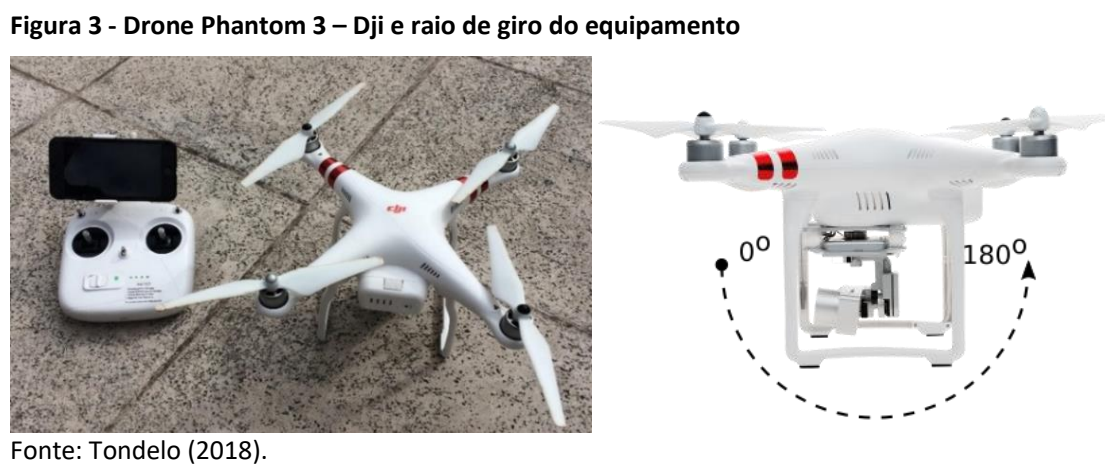

A Figura 4 sintetiza o método de inspeção testado no estudo de caso que consiste em uma adaptação do método proposto por Tondelo (2018), cujas etapas foram baseadas no método proposto por Eschmann et al. (2012).

Figura 4 - Etapas do método testado de inspeção das fachadas
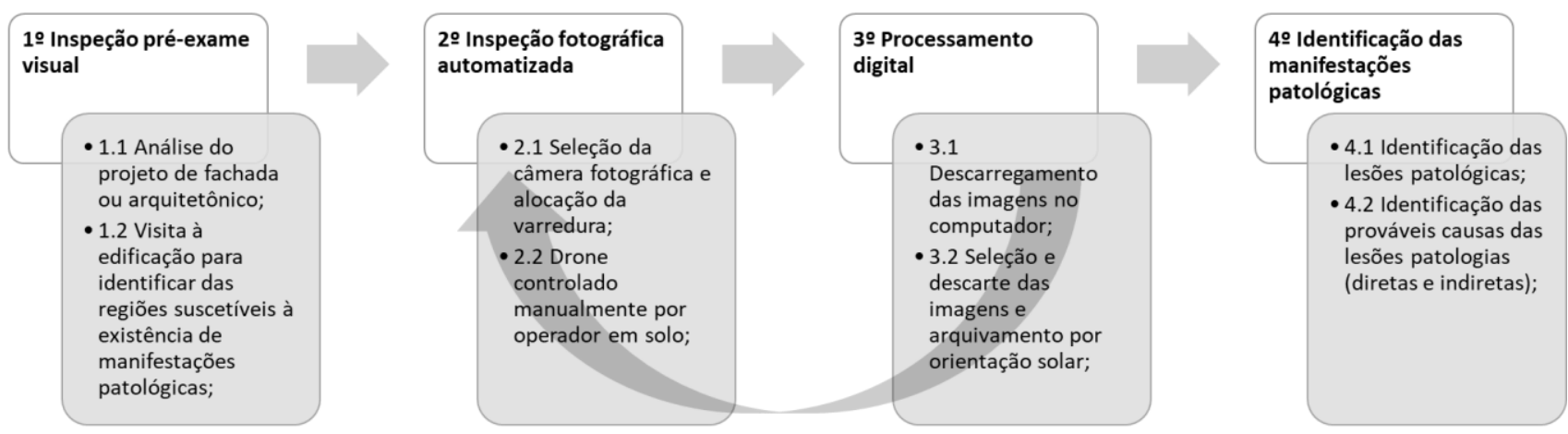

Fonte: Adaptado de Tondelo (2018) e Eschmann et al. (2012).

A primeira etapa, 'Inspeção pré-exame visual', consiste em analisar o projeto de fachada obtido do escritório de arquitetura ou engenharia, bem como realizar visitas à edificação para a identificar as regiões suscetíveis à existência de manifestações patológicas. Indica-se solicitar para análise o projeto de fachada ou, na falta deste, recorrer ao projeto arquitetônico. A segunda etapa, 'Inspeção fotográfica automatizada', abrange a seleção da câmera adequada, alocação da varredura e o registro fotográfico da fachada. Com relação à câmera, pode-se utilizar a câmera do próprio drone ou substituíla por uma câmera térmica. Quanto a alocação da varredura, sua disposição pode ser vertical ou horizontal, a depender dos obstáculos e da geometria dos planos de fachada. 
A terceira etapa engloba o 'Processamento digital', que consiste no descarregamento das fotos da câmera, seguido da seleção, do descarte e do arquivamento sistematizado por fachadas. Entre a segunda e a terceira etapa, foi previsto um ciclo denominado retroalimentação, que pode ser aplicado nos casos em que as fotografias obtidas são pouco esclarecedoras ou insuficientes para identificação das manifestações patológicas. Por fim, a quarta etapa abrange a 'Identificação das manifestações patológicas' por meio da análise individual e minuciosa das fotografias visando detectar as anomalias, sua forma de apresentação e as fachadas em que se mostraram recorrentes.

\section{Caracterização dos aspectos construtivos do estudo de caso}

O edifício analisado, construído em 2011, localiza-se na cidade de Itajaí próximo à desembocadura do rio Itajaí-Açu com o oceano Atlântico. O edifício apresenta 501,82 $\mathrm{m}^{2}$, cerca de $29 \%$ da área de superfície com fachada industrializada com câmara de ar, conforme mostra a Figura 5 .

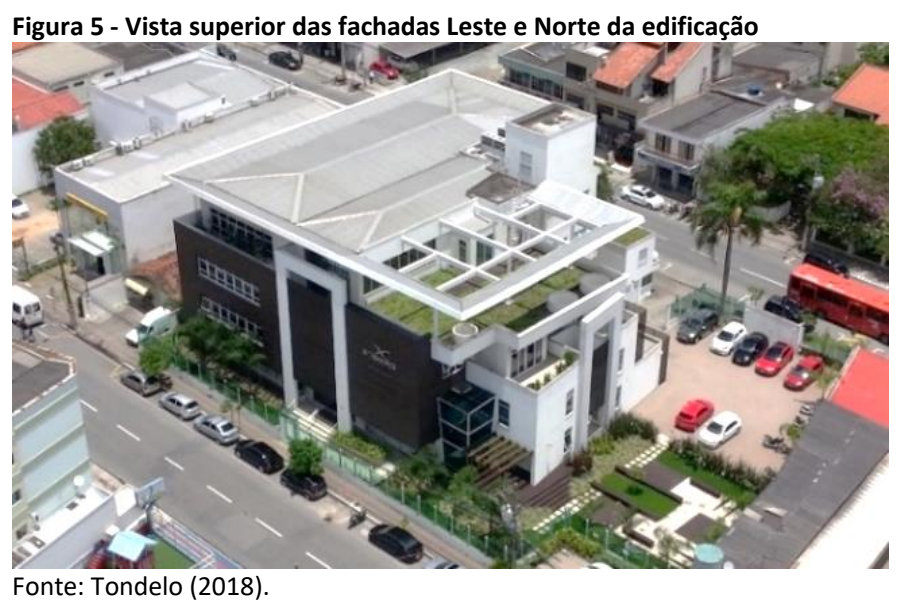

Na Figura 6a são apresentados os subsistemas e elementos construtivos que compõem a fachada industrializada estudada. Os detalhes construtivos foram desenhados pelos autores com base nos dados coletados do projeto arquitetônico, do catálogo do fabricante e de fotografias registradas durante as visitas técnicas, uma vez que o projeto disponibilizado pelo escritório de arquitetura não dispunha de detalhamento suficiente para o entendimento da fachada. Do exterior para o interior tem-se: laminado de fenólico de $1 \mathrm{~cm}$, duto de ar de $10 \mathrm{~cm}$, fixadores em alumínio, camada interna em alvenaria de tijolos rebocada em ambos os lados com espessura aproximada de $13 \mathrm{~cm}$, totalizando $24 \mathrm{~cm}$ na espessura da vedação. Nota-se na Figura 6a, a ausência do subsistema de isolamento térmico e a presença de juntas seladas.

$\mathrm{Na}$ Figura 6b são mostrados os detalhes em seções transversais do peitoril das janelas e do selamento das juntas com delimitador de profundidade em poliuretano e acabamento em silicone. Diferentemente do que será apresentado nos detalhes dos arremates superiores da fachada, identificou-se a ausência do dreno em formato de pingadeira no arremate dos peitoris em granito das janelas. 
Figura 6 - Planta baixa e seção transversal da fachada industrializada (a) e seção transversal do peitoril das janelas e das juntas (b) do estudo de caso
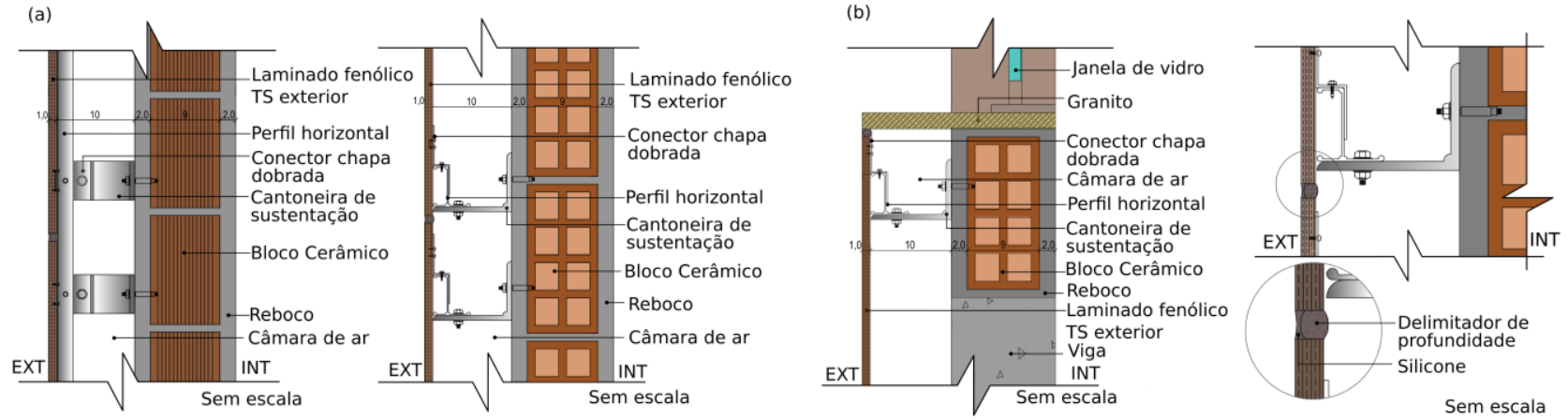

Fonte: Adaptado de Tondelo (2018).

Na Figura 7a e 7b são apresentados os detalhes em seção transversal dos arremates superiores e inferiores. Observa-se a aplicação de dois materiais para confecção dos acabamentos superiores, rufo em chapa metálica dobrada e granito nos locais em que há sacadas. Os locais com granito possuem pingadeira para evitar que a água escorra sobre o revestimento externo. Com relação ao arremate inferior, observa-se que foi utilizada placa fenólica em todo o perímetro da fachada.

Nestas ilustrações também é possível observar a inexistência de um orifício superior específico para saída do ar que em todo o perímetro superior da fachada. De outro modo, observa-se que no arremate inferior foi realizada a perfuração da placa fenólica para entrada do ar na câmara simulando uma grelha.

Figura 7 - Seção transversal dos arremates superiores (a) e seção transversal dos arremates inferiores (b) da fachada do estudo de caso

(a)
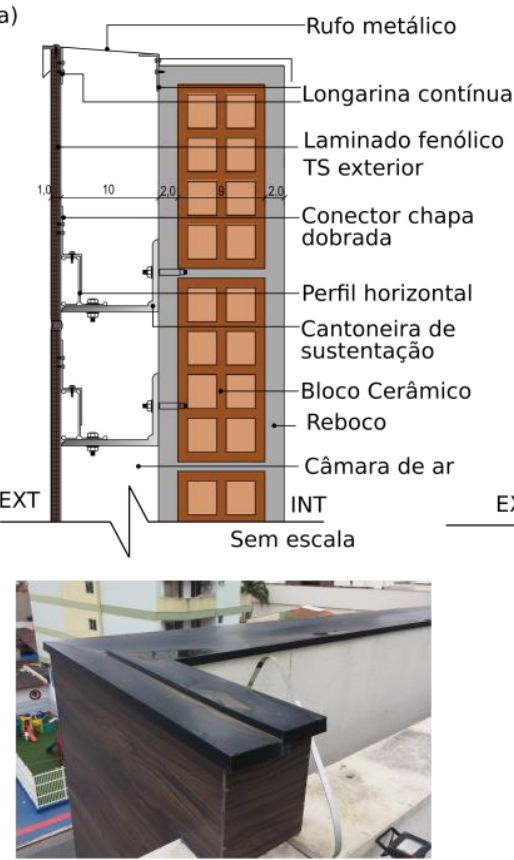
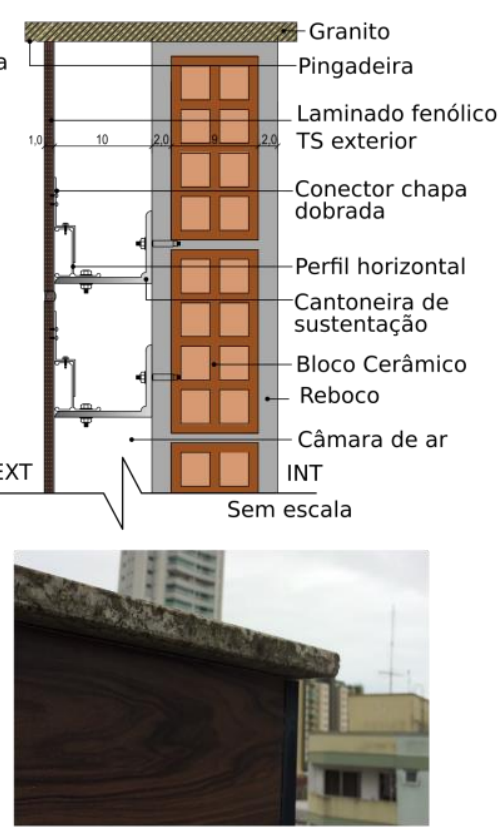

(b)
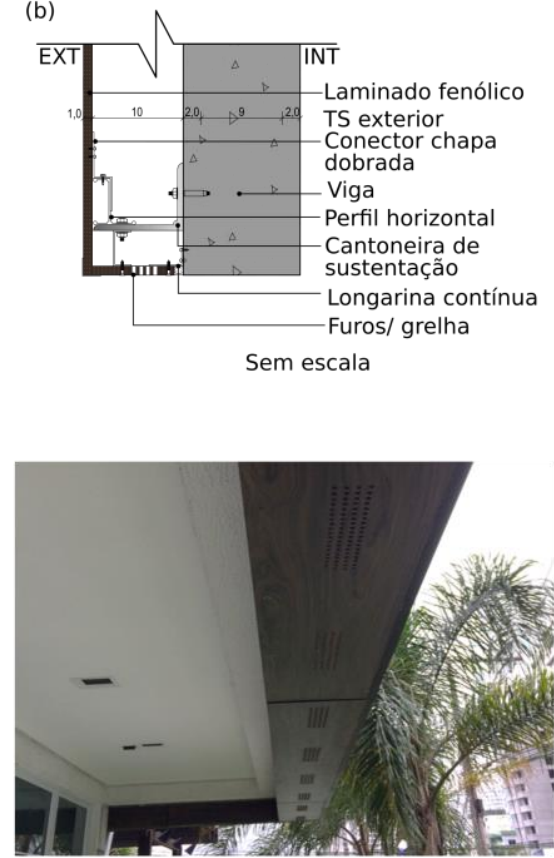

Fonte: Adaptado de Tondelo (2018).

\section{Resultados e discussões}

As inspeções foram realizadas em uma tarde de primavera no dia 07.11.2017. Para tanto utilizou-se a câmera fotográfica do drone com resolução de 12 megapixels. A Figura 8 apresenta a alocação da varredura e a distribuição dos pontos de captura de imagens fotográficas ao longo da fachada industrializada em uma das quatro fachadas 
examinadas. Quanto a distribuição dos pontos, utilizou-se como referência a dimensão padrão das placas fenólicas, adotando-se 1,22 m e 3,07 m como distância vertical e horizontal entre os pontos. Com relação à distância entre o drone em superfície de fachada, adotou-se a medida de $0,8 \mathrm{~m}$.

Figura 8 - Alocação da varredura e distribuição dos pontos de captura de imagens fotográficas na fachada Leste

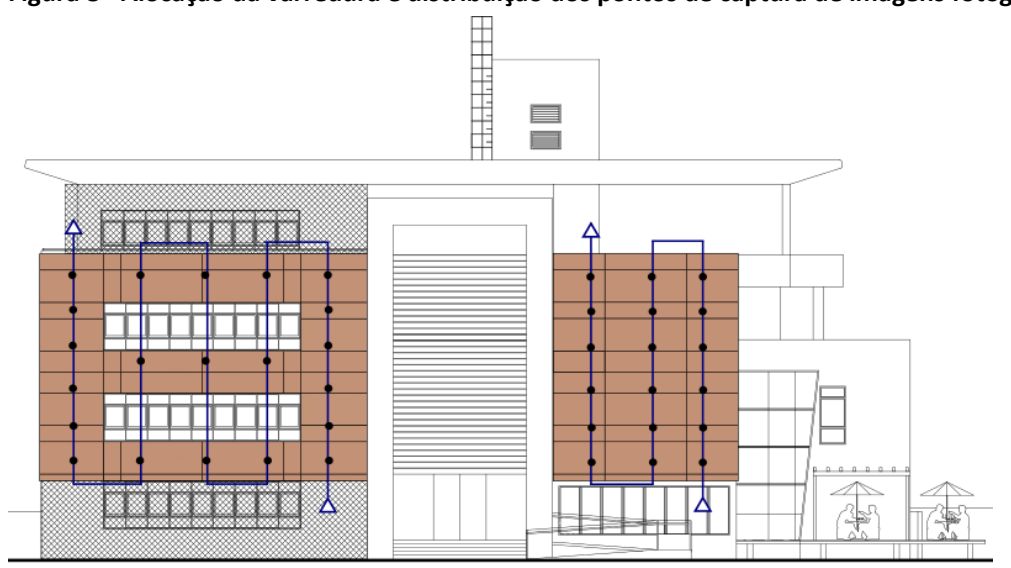

- Pontos de captura das fotografias (48 pontos)

$\triangleright$ Varredura vertical

Fonte: Tondelo (2018)

Observa-se que foram distribuídos 48 pontos na fachada Leste. Para as demais fachadas utilizou-se 53 pontos na fachada Sul, 36 pontos na fachada Oeste e 22 pontos na fachada Norte. As manifestações patológicas detectadas foram agrupadas por fachada de acordo com a orientação solar.

\section{Inspeção da fachada Leste}

$\mathrm{Na}$ fachada Leste identificou-se o acúmulo de sujidades ao longo da superfície do laminado fenólico que se apresentam como manchas brancas, havendo maior incidência na região abaixo do peitoril das janelas, conforme mostra a Figura 9. Quanto a origem destas sujidades, é possível supor que se devem ao meio natural onde a edificação está inserida associada a autolimpeza desuniforme das fachadas. Porém, outro motivo de origem indireta diz respeito aos produtos de limpeza aplicados nos vidros das janelas que escorrem e se acumulam abaixo do peitoril, uma vez que o peitoril das janelas não possui pingadeira.

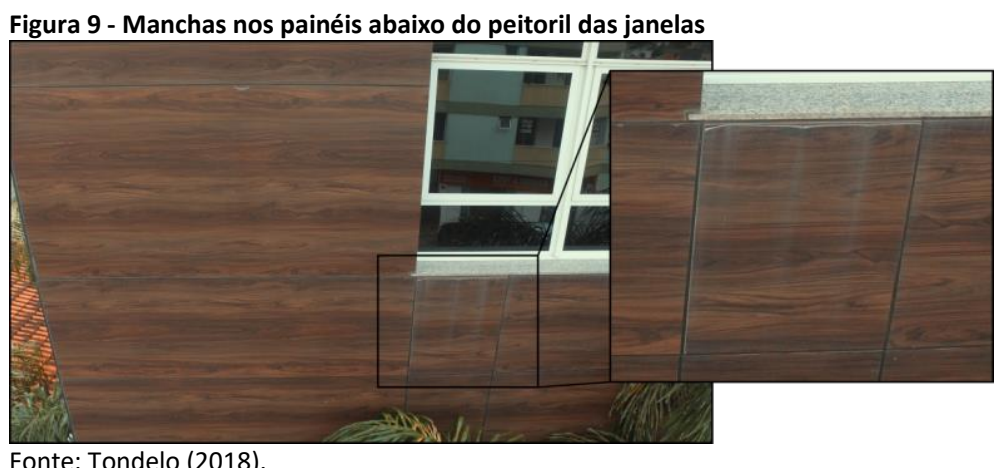

Fonte: Tondelo (2018).

Na Figura 10 pode-se observar manchas brancas na borda dos painéis e a delaminação da película protetora. As manchas concentram-se no entorno das juntas e podem ser resultantes da penetração do material constituinte do selante nas bordas do painel fenólico. As causas da delaminação inter-relacionam ações que podem ter origem nas 
intempéries climáticas, tais como insolação e umidade, entre outros fatores relacionados com o processo de produção ou redimensionamento das placas para composição da paginação. Segundo Thébault et al. (2017), a impregnação incompleta ou heterogênea da resina fenol-formaldeído pode causar perda da resistência mecânica e a delaminação do painel fenólico.

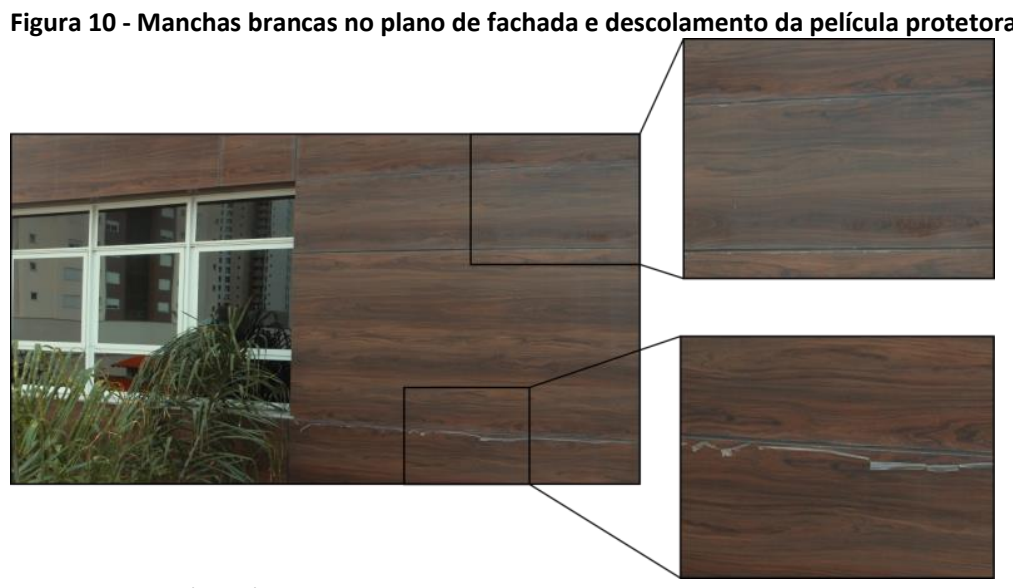

Fonte: Tondelo (2018).

Na Figura 11 pode-se observar o escorrimento que se apresenta na forma de manchas verticais brancas localizadas próximo ao letreiro metálico da logomarca da empresa. Os metais tendem a criar uma camada superficial de óxido metálico quando em contato com o oxigênio que podem escorrer e manchar os painéis com a ação das chuvas. $\mathrm{Na}$ Figura 12 pode-se observar o desprendimento e oxidação do perfil de arremate metálico e o destacamento do delimitador de profundidade em poliuretano. As causas deste desprendimento podem envolver motivos relacionados a execução do projeto, como, por exemplo, a fixação de forma inadequada. Além do desprendimento do perfil, também foram identificadas a descamação da pintura eletrostática e a oxidação do metal de arremate.

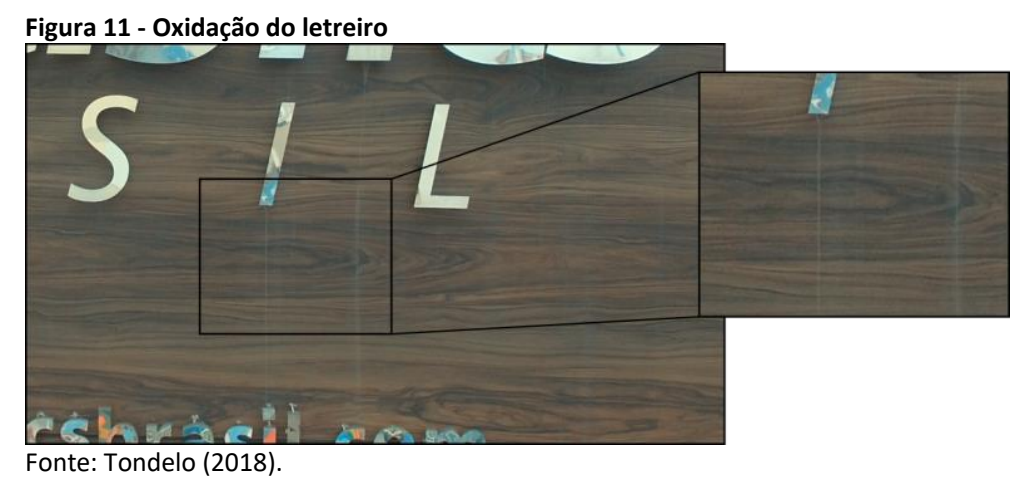

Figura 12 - Desprendimento, oxidação do perfil de arremate metálico e destacamento do delimitador de profundidade

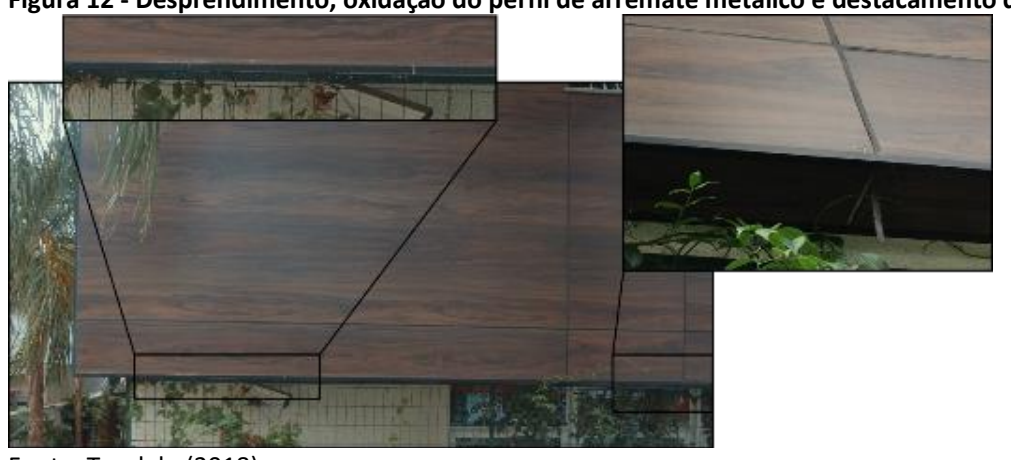

Fonte: Tondelo (2018). 


\section{Inspeção da fachada Sul}

A fachada Sul apresenta manifestações patológicas similares às encontradas na fachada Leste, com exceção da oxidação no letreiro metálico. Na Figura 13 pode-se observar o descolamento da película protetora e o ressecamento das juntas. Também verificou-se a perda de aderência nos painéis fenólicos por parte do selante. Esta perda pode ter sido provocada por falha de execução, sujidade do painel na fase do selamento, ou ainda ressecamento do selante em função dos níveis de exposição à radiação solar.

Na Figura 14 pode-se observar algumas manchas brancas nas bordas dos painéis fenólicos em vários locais ao longo da fachada Sul, constatando-se maior incidência no peitoril das janelas.

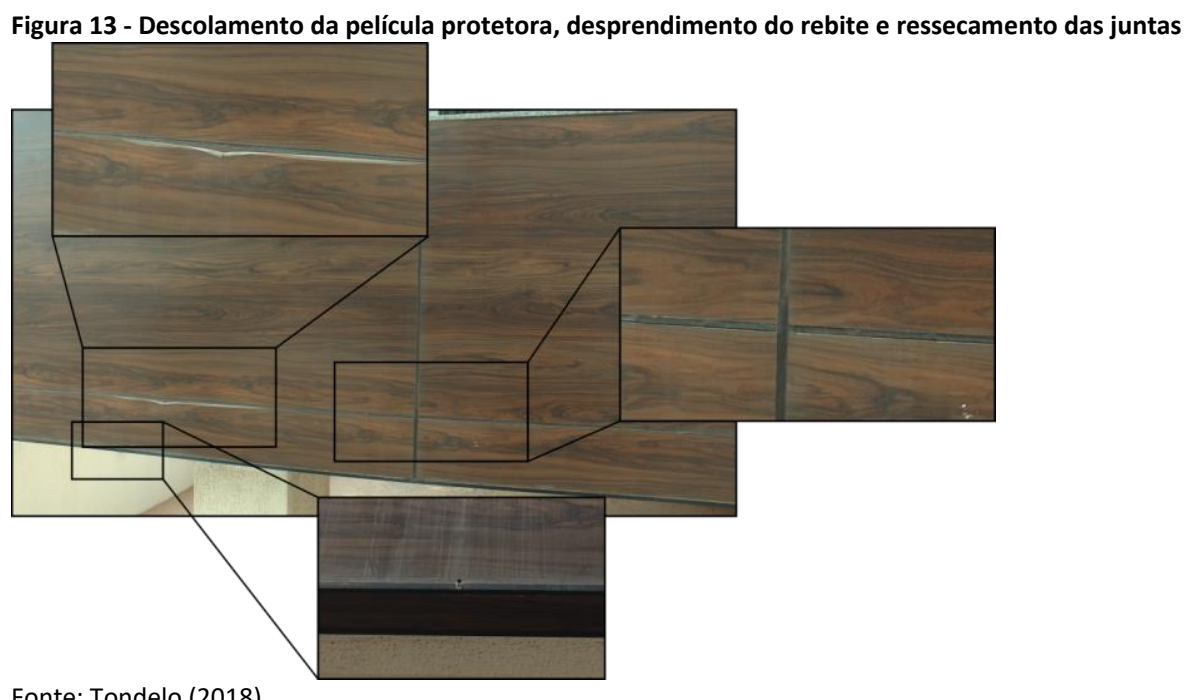

Figura 14 - Manchas brancas na bordas dos painéis e no peitoril das janelas

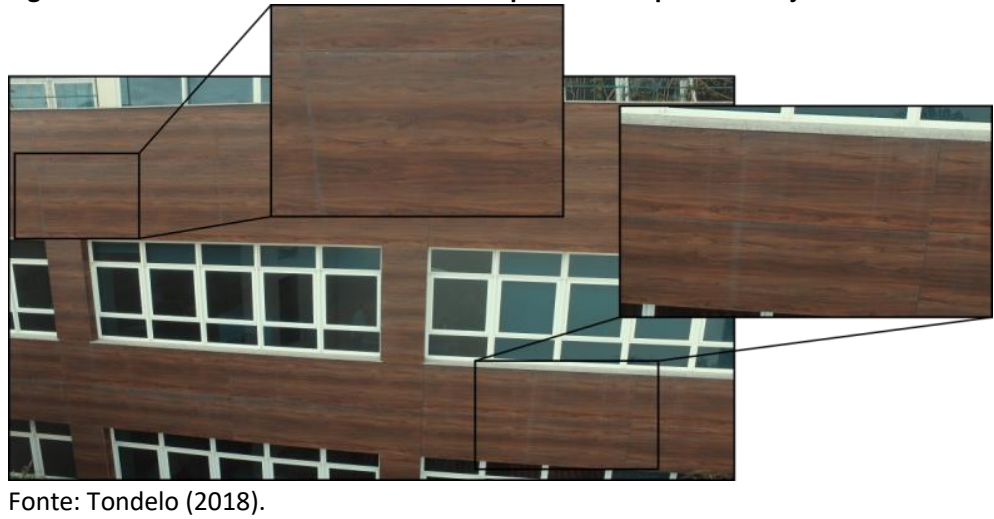

Inspeção da fachada Oeste

A fachada Oeste recebe aproximadamente $6 \mathrm{~h}$ e $30 \mathrm{~min}$ de insolação direta no verão e 3 h e 30 min no inverno'. Esta exposição acentuada contribui para a delaminação da película protetora dos painéis fenólicos, em especial nas regiões da borda inferior. $\mathrm{Na}$ Figura 15 também pode-se observar o destacamento do arremate metálico da borda inferior.

A Figura 16 mostra a presença das manchas brancas nas juntas e a sujidade acumulada na borda inferior do plano de fachada. 
TONDELO, Patricia Geittenes; BARTH, Fernando.

Análise das manifestações patológicas em fachadas por meio de inspeção com VANT

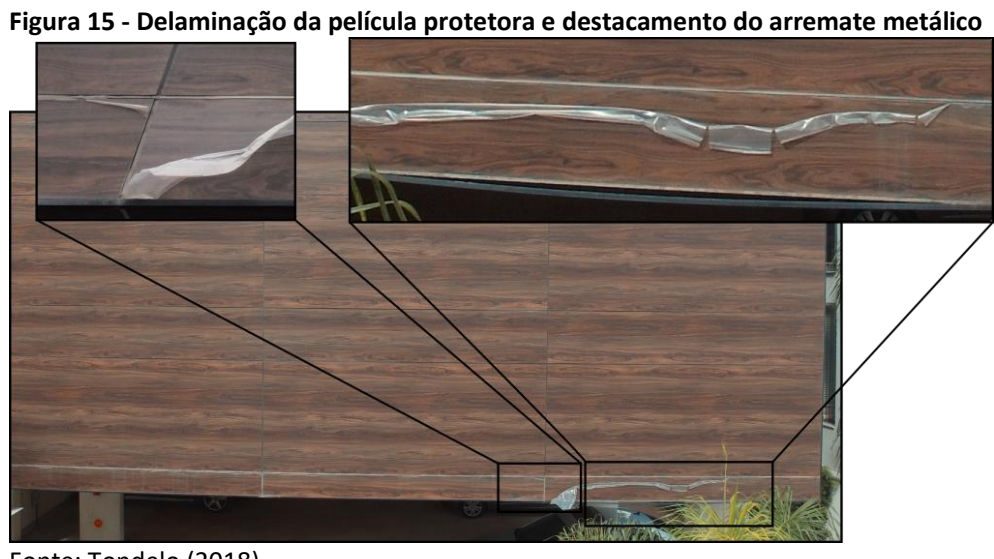

Fonte: Tondelo (2018).

Figura 16 - Manchas brancas nas juntas e acúmulo de sujidades na borda inferior do plano da fachada Oeste

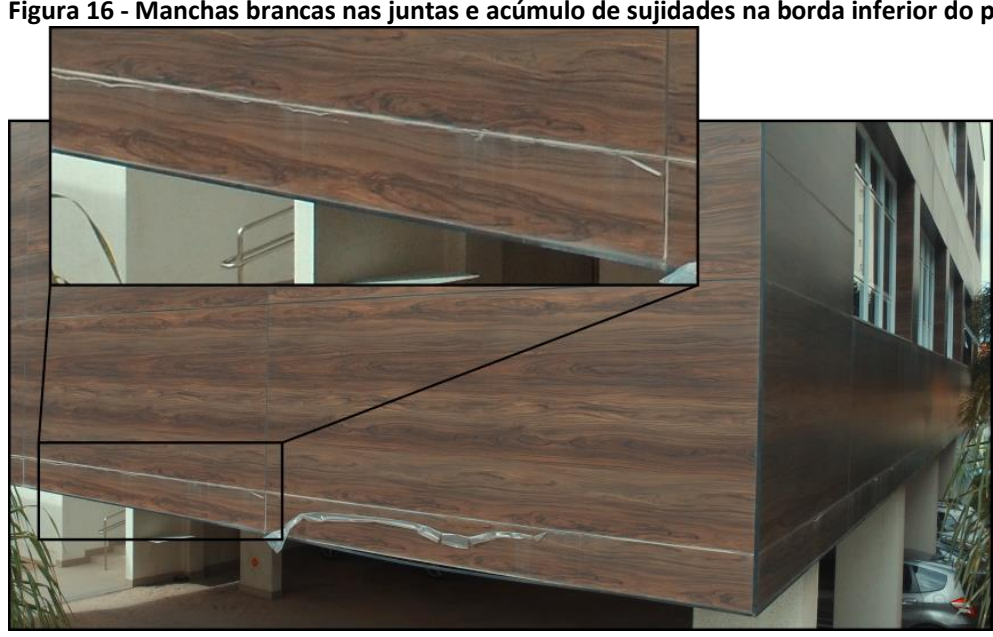

Fonte: Tondelo (2018).

\section{Inspeção da fachada Norte}

A fachada Norte é formada por dois blocos independentes. A parte direita encontra-se diretamente mais exposta ao clima, enquanto a porção esquerda é parcialmente protegida pela marquise que suporta a cobertura vegetal. Na Figura 17 mostra-se a parte direita da fachada, na qual foram detectadas sujidades, juntas ressecadas, desconexão entre o peitoril de granito e a fachada fenólica, assim como fezes de aves em regiões pontuais.

A Figura 18 apresenta a parte esquerda, na qual é possível identificar a aplicação de rebites, o que denota uma fixação incompatível com a adotada no projeto e realizada nas demais fachadas. Próximo à caixa de vidro detectou-se a ausência de material selante nas juntas de encontro entre o vidro e os painéis fenólicos. Devido à existência de uma janela nesta fachada também se identificou a presença de manchas brancas abaixo do peitoril decorrentes de sujidades que podem estar associadas com produtos de limpeza aplicados nos vidros. 


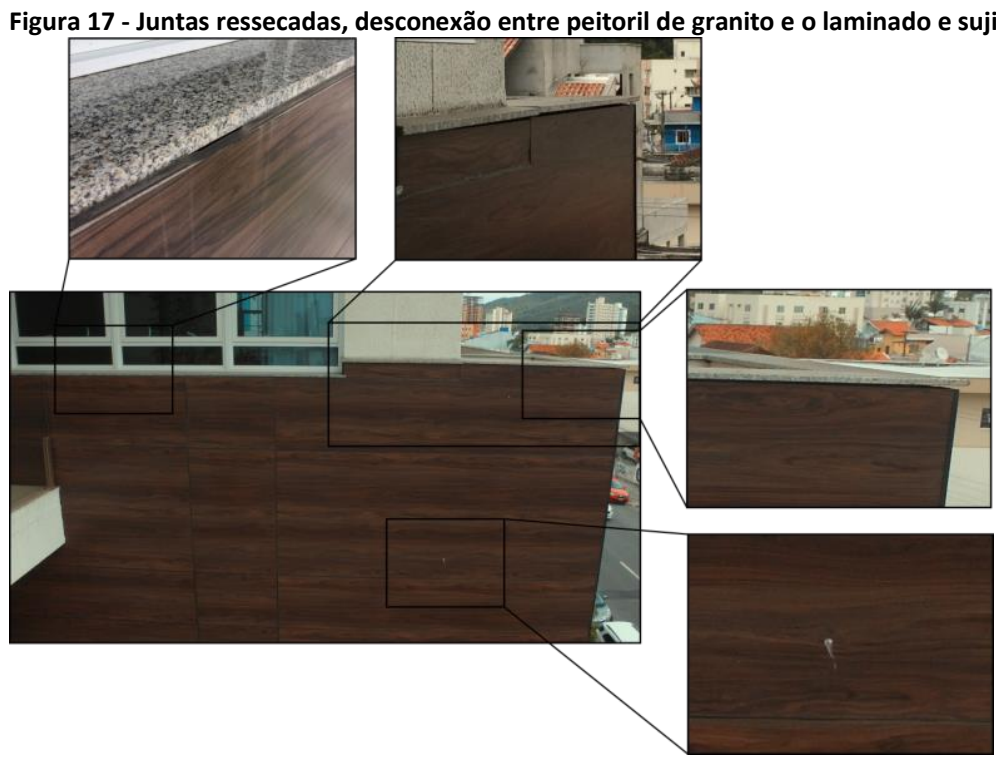

Fonte: Tondelo (2018).

Figura 18 - Rebites amostra, ausência de selante, escorrimento no peitoril da janela

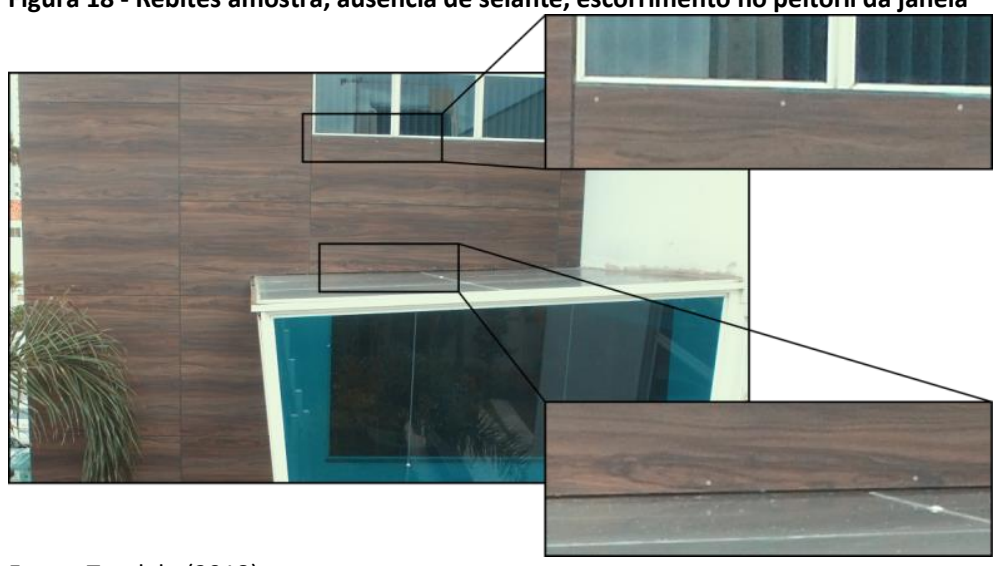

Fonte: Tondelo (2018).

\section{Discussões quanto aos aspectos construtivos}

A falta de detalhes construtivos e projeto de fachada gerou diversas falhas e incongruências, tais como a falta de selante em algumas juntas, peitoris de janelas sem pingadeira, além de fixações rebitadas nos locais com pouca visibilidade que destoam do método de fixação adotado na fachada.

O dimensionamento inadequado dos orifícios de ventilação é outra consequência decorrente da falta de projeto e detalhamento de fachada. Para que ocorra o fenômeno da convecção térmica em edifícios com juntas seladas é necessário que existam aberturas na parte superior e inferior do revestimento externo. Essa condição inexiste na fachada estudada, tendo em vista que o mesmo possui aberturas de ventilação apenas parte inferior do revestimento, o que fisicamente dificulta a convecção por renovação do ar dentro da câmara.

\section{Discussões quanto às manifestações patológicas}

O edifício tem sete anos, sendo que até o presente momento a fachada não recebeu manutenção. Deste modo, é justificável que algumas manifestações patológicas decorrentes do uso e operação sejam observadas, tais como as sujidades, o 
ressecamento do selante, os pontos de oxidação e o desprendimento de acabamentos metálicos. Não obstante, observou-se uma grande quantidade de manifestações patológicas que são de origem indireta, reflexo da falta de projeto e detalhamento de fachada. Ressalta-se que os detalhes construtivos apresentados da fachada industrializada foram desenvolvidos posterior a execução da fachada. Com o intuído de sintetizar as manifestações patológicas detectadas no estudo de caso seguiram-se os termos e as definições de Carrió (1997). O Quadro 1 sintetiza a apresentação das manifestações patológicas, as prováveis causas (direta e indireta) e as fachadas em que estas são recorrentes.

Quadro 1 - Síntese da forma de apresentação manifestação patológica com suas prováveis causas e fachadas recorrentes

\begin{tabular}{|c|c|c|c|c|c|}
\hline \multicolumn{2}{|r|}{ Manifestações patológicas } & \multirow{2}{*}{\multicolumn{4}{|c|}{$\begin{array}{l}\text { Incidência } \\
\text { Fachada }\end{array}$}} \\
\hline \multirow{2}{*}{$\begin{array}{l}\text { Forma de apresentação } \\
\text { da manifestação patológica }\end{array}$} & \multirow{2}{*}{$\begin{array}{l}\text { Prováveis causas } \\
\text { (Diretas e Indiretas) }\end{array}$} & & & & \\
\hline & & $\mathrm{L}$ & $\mathrm{S}$ & $\mathrm{O}$ & $\mathrm{N}$ \\
\hline $\begin{array}{l}\text { Manchas brancas abaixo do } \\
\text { peitoril das janelas }\end{array}$ & $\begin{array}{l}\text { Diretas: Partículas decorrentes do meio em que a edificação está } \\
\text { inserida } \\
\text { Indiretas: Produtos de limpeza aplicados nos vidros das janelas }\end{array}$ & $\mathrm{x}$ & $\mathrm{X}$ & & $x$ \\
\hline $\begin{array}{l}\text { Acúmulo de sujidades na } \\
\text { parte inferior dos planos de } \\
\text { fachadas }\end{array}$ & $\begin{array}{l}\text { Diretas: Partículas decorrentes do meio em que a edificação está } \\
\text { inserida }\end{array}$ & $\mathrm{x}$ & $\mathrm{X}$ & $\mathrm{x}$ & $\mathrm{X}$ \\
\hline $\begin{array}{l}\text { Manchas nas bordas dos } \\
\text { painéis pelo material } \\
\text { constituinte do selante }\end{array}$ & $\begin{array}{l}\text { Indiretas: Penetração do material constituinte do selante nas } \\
\text { bordas dos painéis devido ao redimensionamento das peças }\end{array}$ & $x$ & $\mathrm{X}$ & $x$ & $x$ \\
\hline $\begin{array}{l}\text { Delaminação da película } \\
\text { protetora }\end{array}$ & $\begin{array}{c}\text { Diretas: Intempéries climáticas } \\
\text { Indiretas: Manufaturação do produto e redimensionamento dos } \\
\text { painéis }\end{array}$ & $x$ & $\mathrm{X}$ & $\mathrm{x}$ & \\
\hline $\begin{array}{l}\text { Desprendimento e oxidação } \\
\text { do perfil metálico de } \\
\text { arremate }\end{array}$ & $\begin{array}{l}\text { Diretas: Metal em contato com o oxigênio } \\
\text { Indiretas: Falhas na execução }\end{array}$ & $\mathrm{x}$ & $\mathrm{X}$ & $x$ & \\
\hline Rebites expostos & Indiretas: Falhas projetuais e falhas de execução & & & & $x$ \\
\hline Oxidação do letreiro & Diretas: Metal em contato com o oxigênio & $x$ & & & \\
\hline Ausência de selante & Indiretas: Falhas de execução & & & & $x$ \\
\hline Ressecamento das juntas & $\begin{array}{l}\text { Diretas: Sujidade excessiva e altos níveis de exposição solar } \\
\text { Indiretas: Falhas de execução e manutenção ou validade } \\
\text { ultrapassada do selante }\end{array}$ & $x$ & $\mathrm{X}$ & $x$ & $x$ \\
\hline
\end{tabular}

Fonte: Tondelo (2018).

\section{Discussões quanto ao método de inspeção de fachadas}

A inspeção dos locais mais altos das edificações por métodos tradicionais demanda uma logística que envolve a locação, montagem e desmontagem de andaimes, escadas e equipamentos de segurança, assim como a execução por meio de mão de obra qualificada. Com aplicação dos VANTs, esta logística simplifica-se com a utilização de um único aparelho manipulado por um operador qualificado e orientado um profissional da área. De outro modo, toda essa celeridade e simplificação que os drones possibilitam na inspeção de fachadas pode ser prejudicada por condições climáticas desfavoráveis e existência de obstáculos próximos às fachadas. Fatores como o vento e a chuva, por exemplo, podem dificultar ou até mesmo impedir a realização da inspeção.

No estudo em questão, a existência de árvores próximas as fachadas Leste e Sul somada a presença de fiação elétrica e de uma edificação geminada dificultaram a inspeção destas fachadas, resultando em desvios da rota pré-definida, fotografias mais distantes e com qualidade de resolução inferior. A Figura 19 mostra os obstáculos encontrados nas fachadas Leste e Sul. Somado a isso, o drone utilizado apresentou dificuldades de 
decolagem nos locais próximos a fachada Leste devido à interferência de sinal gerada pelos metais e vidros do entorno. Observa-se que alguns obstáculos, tais como as árvores e arbustos podem ter seu volume diminuído através de podas e gerar menor influência durante a inspeção.

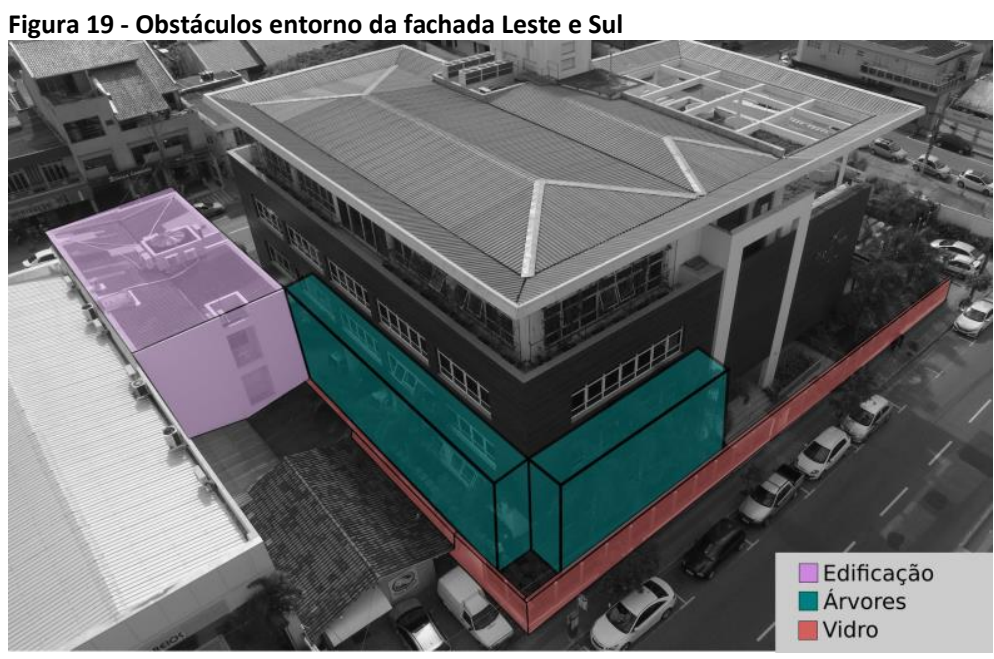

Fonte: Adaptado de Tondelo (2018).

A câmera do drone permite a obtenção de imagens por meio de duas técnicas: vídeo e fotografias. Deste modo, antes de iniciar a inspeção, testou-se a aplicação destas duas técnicas. A primeira caracteriza-se pela filmagem da fachada e posterior obtenção das fotografias por meio de frames (capturas instantâneas) dos locais identificados com manifestações patológicas. A segunda caracteriza-se pelo voo seguido de estabilização do equipamento no ar para obtenção das fotos da região desejada. A primeira técnica de obtenção de fotos se mostrou menos eficiente do que a segunda em virtude da baixa resolução das imagens geradas pelo vídeo seguido da captura instantânea. A segunda técnica, embora de execução mais demorada, se mostrou mais eficaz, pois a resolução das fotos permitiu a identificação das manifestações patológicas. As Figuras 20a e 20b apresentam as duas técnicas de obtenção das imagens. Constata-se que a resolução da fotografia obtida pelos frames possui qualidade inferior comparada à fotografia obtida pelo voo seguido de paradas.

Figura 20 - Técnicas obtenção das fotos testadas: (a) Foto obtida a partir do vídeo: qualidade inferior e (b) foto obtida com o posicionamento do drone no ar: qualidade superior
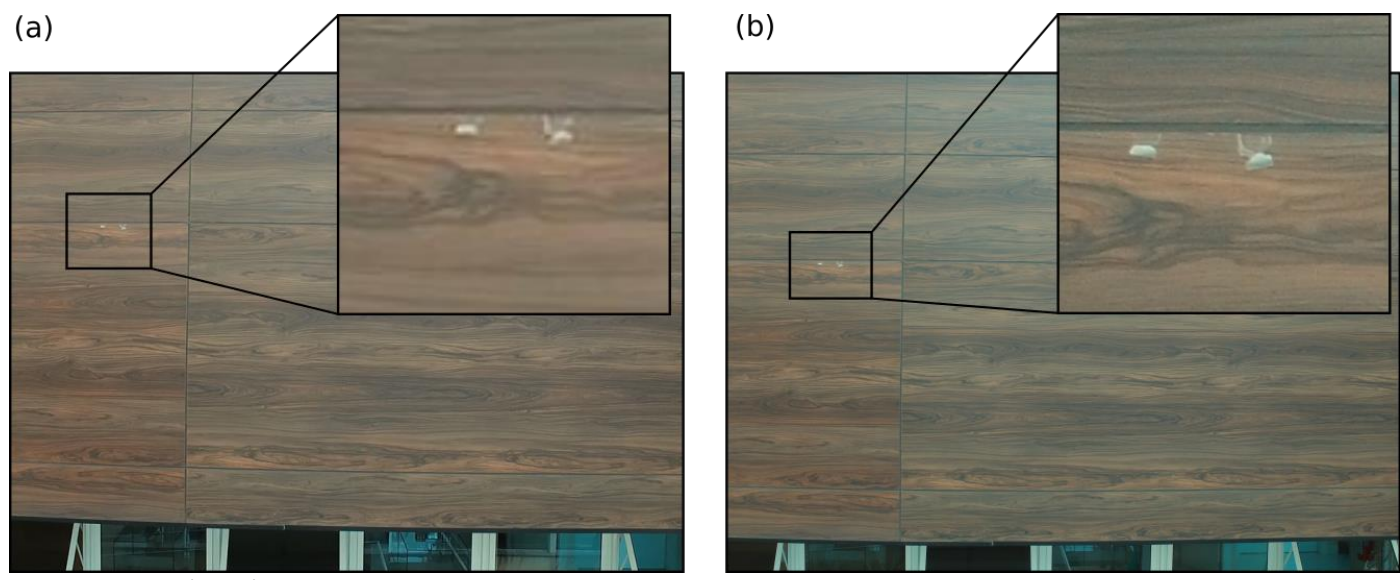

Fonte: Tondelo (2018).

A câmera utilizada na inspeção foi a do próprio drone. Outra possibilidade é substituir da câmera do equipamento por outra termográfica, uma vez que pode permitir a obtenção de resultados mais precisos como identificação de manifestações patológicas 
na face posterior do revestimento fenólico. Com o uso de câmeras térmicas, também é possível obter resultados mais pertinentes com relação ao diagnóstico das anomalias.

A manipulação e o controle do equipamento VANT foi realizada manualmente pelo técnico contratado. Outra opção é a utilização da ferramenta de Global Positioning System (GPS), no qual se define um plano de voo para guiar o drone durante a inspeção. Esta opção foi descartada de devido à presença de obstáculos próximo as fachadas e ao intenso tráfego de veículos e pessoas nas proximidades do edifício.

A Figura 21 apresenta a alocação, o sentido da varredura e a distribuição dos pontos para obtenção das imagens nas quatro fachadas examinadas. Em preto são os pontos em que o drone realizou as paradas para obtenção das imagens, em vermelho são os pontos prejudicados pelos obstáculos no entorno do edifício e a linha em azul é o sentido da varredura. Observa-se que dos 48 pontos fachada da Leste, 3 foram prejudicados e que dos 53 da fachada Sul, 13 foram dificultados por obstáculos.

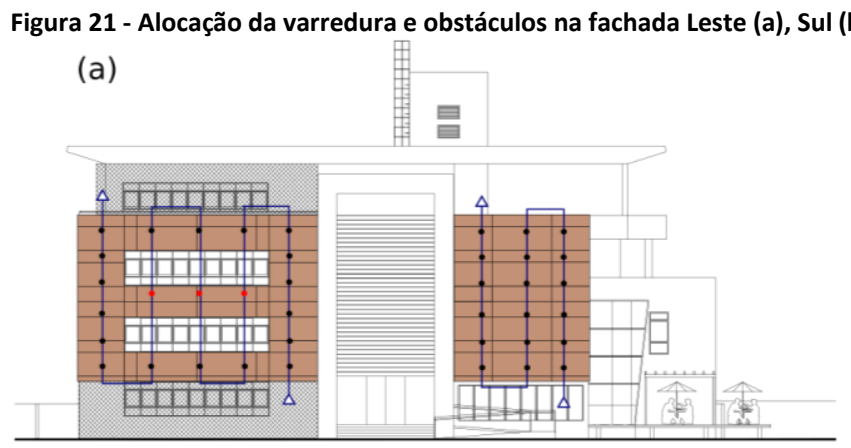

- Pontos de captura das fotografias (48 pontos)

- Pontos prejudicados por obstáculos (3 pontos) $\triangleright$ Varredura vertical (b)

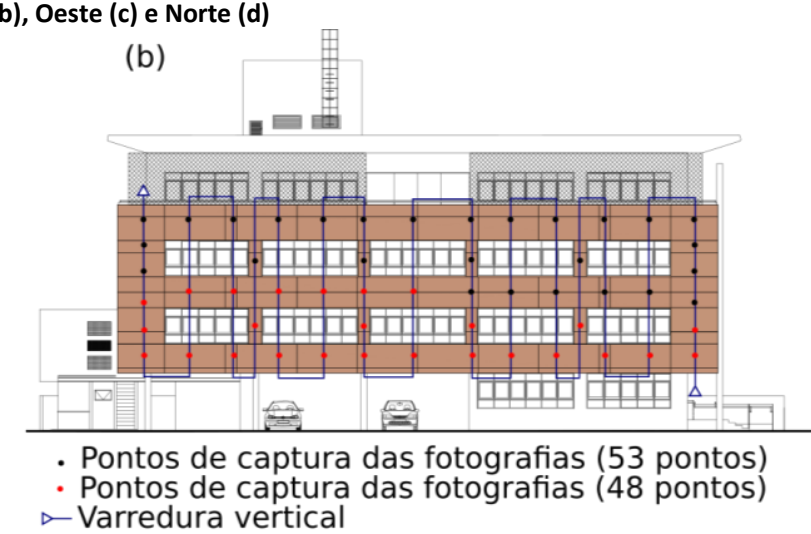

(d)

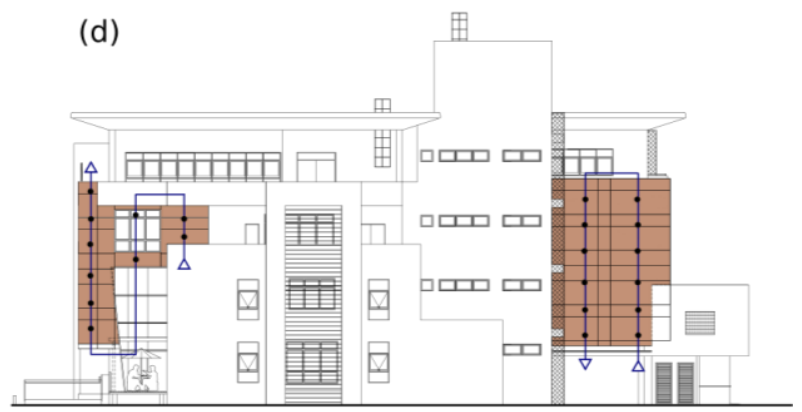

- Pontos de captura das fotografias (22 pontos)

- Pontos prejudicados por obstáculos (0 pontos) $\triangleright$ Varredura vertical

- Pontos prejudicados por obstáculos (0 pontos)

$\triangleright$ Varredura vertical

Fonte: Adaptado de Tondelo (2018).

Quando os planos de fachada são livres de obstáculos, torna-se possível a utilização do GPS. Tal ferramenta permite que as imagens capturadas pelo drone sejam lidas por softwares de geoprocessamento nos moldes utilizados na agrimensura. Esses softwares funcionam por técnicas de costura das imagens baseadas no reconhecimento de padrões semelhantes nas imagens, denominados pontos em comum, que servem como parâmetro de conexão para composição do mosaico da fachada.

\section{Conclusões}

Neste artigo, a durabilidade das fachadas industrializadas com câmara de ar foi explorada por meio de análises que abordaram os aspectos construtivos e a inspeção das manifestações patológicas deste subsistema construtivo. Para a detecção das 
anomalias testou-se a aplicação de um método de inspeção de fachadas auxiliados por Veículos Aéreos Não Tripulados.

Observa-se que a falta de detalhamento do projeto destas fachadas resultou em incongruências projetuais, como, por exemplo, os locais em que as formas de fixação do revestimento externo eram diferentes da adotada na maior parte da fachada, a ausência, ausência de elementos e detalhes construtivos como isolante térmico e a pingadeira no peitoril das janelas, falta de material selante em algumas juntas, assim como os orifícios inadequados nos painéis para propiciar sua ventilação. A câmara de ar estático não traz grandes benefícios higrotérmicos ao edifício, uma vez que possui orifícios de ventilação apenas na parte inferior do revestimento externo. Para que a câmara se torne convectiva, mostra-se necessária a perfuração da região superior do plano de fachada para promover sua ventilação.

Os resultados referentes a inspeção das fachadas mostraram que a ausência de detalhamentos também corroborou para o aparecimento de manifestações patológicas indiretas, uma vez que a falta de um projeto para guiar a montagem da fachada acarretou em falhas durante sua execução. Dentre as manifestações patológicas indiretas detectadas no estudo, a delaminação da película protetora destaca-se como a situação mais preocupante. Nota-se que o nível de degradação das placas fenólicas de algumas fachadas compromete aspectos compositivos e estéticos, bem como a funcionalidade do revestimento externo.

Com relação ao método de inspeção auxiliado por VANT, observou-se que este se mostrou eficiente para identificação das manifestações patológicas. Com o drone foi possível realizar uma inspeção mais rápida dos planos de fachadas, incluindo os locais de difícil acesso. Não obstante a eficiência do equipamento, para maior precisão na identificação manifestações patológicas, mostra-se necessário realizar ensaios laboratoriais específicos que podem envolver métodos destrutivos, ou ainda, pode-se também substituir da câmera do equipamento por outra específica para identificação de outras anomalias, como por exemplo as câmeras de infravermelho.

Outro ponto importante com relação à utilização dos VANTs em inspeções de fachadas é a possibilidade de mapear de documentar o estado de conservação do edifício por meio do registro dos danos encontrados, uma vez que as fotografias obtidas permitem que sejam elaborados mapas de danos, similares aos aplicados para mapear os danos em edifícios históricos.

Como desdobramento desta pesquisa destacamos a necessidade de estudos que abordem a aplicação do drone no modo GPS para a confecção de mapas de danos por meio de métodos de costura ou mosaicos com as imagens através de softwares específicos. Por fim, espera-se que esta pesquisa de análise técnica possa servir de subsídio para pesquisas futuras e para o uso de drones na inspeção de fachadas no país, uma vez que se observa que os VANTs apresentam potencial para serem utilizados como ferramenta de auxílio para do monitoramento desempenho dos edifícios ao longo do tempo.

\section{Agradecimentos}

Agradecimento à CAPES, pelo apoio a esta pesquisa através da concessão de bolsa de estudo. 


\section{Notas}

(1) Dados obtidos a partir da análise da carta solar para a cidade de Florianópolis pelo programa Analysis SOL-AR, e disponibilizado no site do Laboratório de Eficiência Energética da UFSC - LabEEE (http://www.labeee.ufsc.br).

\section{Referências}

ALBUQUERQUE, Pedro Filipe Quental de. Painéis fenólicos para aplicação em fachadas exteriores. $2013.100 \mathrm{f}$. Dissertação (Mestrado) - Curso de Engenharia Civil, Engenharia Civil, Instituto Superior de Engenharia de Lisboa, Lisboa, 2013. Disponível em: https://repositorio.ipl.pt/bitstream/10400.21/3084/1/Disserta\%C3\%A7\%C3\%A30.pdf. Acesso em: 15 jan. 2019.

BARTH, Fernando; VEFAGO, Luiz Maccarini. Tecnologia de fachadas pré-fabricadas. Florianópolis: UfsC, 2016.257 p.

CARRAMIÑANA, Carlos Pérez et al. Ventilated Stone Veneer: Mechanical Behaviour, Calculation Methodologies, Major Pathologies and Existing Tests. In: DBMC INTERNATIONAL CONFERENCE ON DURABILITY OF BUILDING MATERIALS AND COMPONENTS, 12., 2011, Porto. Proceedings [...]. Porto: Feup Edições, 2011. v. 2, p. 01 - 06

CARRIÓ, Juan Monjo. Patologia de cerramientos y acabados arquitectonicos. 2.ed. Madri: Munilla-lería, 1997. 399 p.

ESCHMANN et al. Unmanned Aircraft Systems for Remote Building Inspection and Monitoring. In: EUROPEAN WORKSHOP ON STRUCTURAL HEALTH MONITORING, 6., 2012, Dresden. Proceedings [...]. Berlim: Dgzfp, 2012. v. 2, p. 01 - 08.

GOMIDE, Tito Lívio Ferreira; FAGUNDES NETO, Jerônimo Cabral Pereira; GULLO, Marco Antônio. Normas técnicas para engenharia diagnóstica em edificações. 2. ed. São Paulo: Pini, 2009. 245 p.

GUIA, Luiz Pinheiro da; PEREIRA, Paulo Henrique Cruz. Metodologia para formação de profissionais em inspeção de fachadas em edificações utilizando a robótica móvel. In: INTERNATIONAL CONFERENCE ON ENGINEERING AND TECHNOLOGY EDUCATION, 14., 2016, Salvador. Anais [...]. Salvador: Intertech, 2016. v. 14, p. 203 - 205.

IBAÑEZ-PUY, María et al. Opaque Ventilated Façades: Thermal and energy performance review. Renewable and Sustainable Energy Reviews, [s.l.], v. 79, p.180-191, nov. 2017. Elsevier BV. DOI:http://dx.doi.org/10.1016/j.rser.2017.05.059.

LICHTENSTEIN, Norberto Blumenfeld. Patologia das construções. 06. ed. São Paulo: Usp, 1986. 35 p.

MAS, Ángeles et al. Design and construction recommendations to improve impermeability in rainscreen walls built with natural stone coverings. Construction and Building Materials, [s.l.], v. 25, n. 4, p.1753-1761, abr. 2011. Elsevier BV. DOI:http://dx.doi.org/10.1016/j.conbuildmat.2010.11.091.

SANJUAN, Cristina et al. Experimental analysis of natural convection in open joint ventilated façades with 2D PIV. Building and Environment, [s.I.], v. 46, n. 11, p.2314-2325, nov. 2011. Elsevier BV. DOI:http://dx.doi.org/10.1016/j.buildenv.2011.05.014.

THÉBAULT, Marion et al. Factors influencing the processing and technological properties of laminates based on phenolic resin impregnated papers. European Journal of Wood and Wood Products, [s.l.], v. 75, n. 5, p.785-806, 24 maio 2017. Springer Nature. DOI:http://dx.doi.org/10.1007/s00107-017-1205-8.

TONDELO, Patrícia Geittenes. Fachadas industrializadas com câmara de ar: Análise dos aspectos projetuais, construtivos e dos processos de inspeção e manutenção em dois edifícios no litoral de Santa Catarina. 2018. 140 f. Dissertação (Mestrado) - Curso de Arquitetura e Urbanismo, Centro Tecnológico, Universidade Federal de Santa Catarina, Florianópolis, 2018. 
TONDELO, Patricia Geittenes; BARTH, Fernando.

Análise das manifestações patológicas em fachadas por meio de inspeção com VANT

\section{${ }^{1}$ Patricia Geittenes Tondelo}

Arquiteta e Urbanista. Mestre em Arquitetura e Urbanismo pela Universidade Federal de Santa Catarina. Endereço postal: Rua Laguna, 222, Itajaí, Brasil, 88301460

\section{${ }^{2}$ Fernando Barth}

Engenheiro Civil. Doutor em Construções Arquitetônicas pela Universitat Politecnica de Catalunya. Professor na Universidade Federal de Santa Catarina, Centro Tecnológico, Departamento de Arquitetura. Endereço profissional: Departamento de Arquitetura e Urbanismo, Centro Tecnológico - UFSC, Florianópolis, SC, Brasil, 88040-900 